\title{
Inspeção das Manifestações Patológicas em Estruturas de Concreto Armado no Edifício Bom Pastor em Garanhuns-PE
}

\author{
Inspection of Pathological Manifestations in Reinforced Concrete Structures on Bom
} Pastor Building in Garanhuns - PE

\section{Marília Bezerra ${ }^{1}$ (D) orcid.org/0000-0001-6709-6877}

\author{
Marília Albuquerque ${ }^{1}$ (iD orcid.org/0000-0002-6775-4603 \\ Ricardo Cavalcanti ${ }^{2}$ (id orcid.org/0000-0001-5861-090X
}

\author{
Eliana Monteiro ${ }^{2}$ (D) orcid.org/0000-0003-0842-779X \\ 1 Programa de Pós-graduação em Inspeções, Manutenções e Recuperações das Estruturas pela Universidade de Pernambuco, Recife, \\ Brasil, \\ 2 Departamento de Engenharia Civil, Universidade de Pernambuco, Recife, Brasil.
}

E-mail do autor principal: Marília Marques Pessoa Bezerra mariliamarquespb@gmail.com

\section{Resumo}

O ramo da patologia das estruturas busca promover a segurança e funcionalidade das construções, incentivado pesquisas para diagnósticos das manifestações patológicas das estruturas e maneiras de recuperação, evitando a reincidência de sua deterioração. As construções antigas tendem a sofrer maior quantidade destas manifestações, sejam por ações humanas ou devido a sua exposição ao longo do tempo, como no caso do Edifício Bom Pastor, localizado na cidade de Garanhuns - PE. Este edifício, inaugurado em 1911, teve grande influência para a sociedade, porém hoje encontra-se abandonado pelo governo, onde famílias desabrigadas o ocupam. Esta pesquisa tem o intuito em colaborar com a investigação das atuais condições das estruturas do edifício investigando se há presença de manifestações patológicas e revelar se está apta a servir como moradia funcional. Foram realizadas inspeções em estruturas de concreto armado no edifício Bom Pastor e ensaios em campo como: ensaio de dureza superficial, profundidade de carbonatação e a aspersão de nitrato de prata. Foram comprovadas a presença de corrosão generalizada das armaduras, trincas de corrosão, aparecimento de bolor, eflorescência e baixa qualidade do concreto, o que afetam o bom desempenho da estrutura e sua durabilidade, podendo causar riscos tanto a saúde quanto a segurança dos usuários.

Palavras-Chave: Manifestações Patológicas. Concreto armado. Edifício Bom Pastor;

\section{Abstract}


The pathology of structures aims to promote safety and functionality for constructions and incentivize researches about both diagnostics methods on the pathologic aspects and retrofit methods in order to avoiding it of happening again. Old constructions tend to present many structural pathologies due to physical, chemical, and biological attack as a result of their exposure to natural agents over time, as it is the case of the Bom Pastor Building located in Garanhuns - PE. This building, inaugurated in 1911, had great influence on the local society, nowadays is found abandoned by the Government and was invaded by shelter-less families. This senior thesis aims to collaborate with the investigation of the current situation of Building's structure, to prove the presence of pathologies, and conclude if the building is suitable to serve as housing to the families. Preliminary inspections of the building's structure were carried out and complemented with field tests, such as: Turner-sclerometer test, carbonation depth and silver nitrate. Pathologies were detected on the building's structure such as general corrosion of the rebars, corrosion cracks, mold, efflorescence, low quality of concrete, which all affect the proper performance of the structure and its durability, compromising the health and safety of users.

Key-words: Pathological Manifestations. Reinforced concrete. Bom Pastor Building.

\section{Introdução}

O ramo da patologia das estruturas, remete ao estudo das anomalias ou falhas de elementos da construção civil. Estuda suas causas, consequências e classifica-as de modo a tornar o diagnóstico mais preciso. De acordo com os pesquisadores Lima e Siqueira, este ramo tem crescido no meio da engenharia com fins de aumentar a durabilidade das estruturas, de forma ambientalmente correta [1].

O comitê 201 do ACI (1991) define durabilidade como a capacidade de uma estrutura atender ao desempenho acima dos níveis mínimos de qualidade, resistindo a ações de deterioração e de utilização quando exposto aos efeitos da agressividade ambiental.

O termo manifestação patológica, segundo Moreira é sinônimo da palavra doença, e na área da construção civil a doença do concreto está relacionada a falhas estéticas, defeitos e anomalias indesejáveis, que podem levar tanto ao desconforto dos usuários quanto a inutilização da estrutura [2].

As manifestações patológicas em estruturas de concreto armado podem surgir por diversos fatores, assim como a combinação entre eles, que agem pela exposição do concreto ou determinadas por suas propriedades. Podendo se difundir por deterioração mecânica, física, processos químicos, biológicos e eletromagnéticos.
Segundo Souza e Ripper [3], as causas podem ser classificadas por intrínsecas, as quais estão ligadas as transformações e falhas geradas a partir dos componentes físicos da estrutura, principalmente pelos materiais, forma de execução, ações humanas e ações externas; ou causas por deteriorações extrínsecas, pertinentes às ações que independem das propriedades do concreto, atacam a estrutura durante a sua vida útil.

Construções antigas, tendem a apresentar maior ocorrência de problemas patológicos, devido ao desgaste gerado pela interação com meio ambiente em que a estrutura está inserida. Essas estruturas trazem consigo memórias culturais, arquitetônicas e científicas.

O caso do prédio Bom Pastor, com mais de cem anos de existência, reflete bem esse panorama. Localizado na cidade de Garanhuns - Pernambuco, teve papel influente na sociedade. Serviu desde institutos profissionalizantes até abrigos para famílias estrangeiras. Hoje, abandonado pelo governo do Estado, encontra-se em estado precário onde famílias desabrigadas o ocupam.

O presente trabalho busca colaborar com a investigação das atuais condições do prédio do Bom Pastor, identificar manifestações patológicas e problemas atuantes, e determinar se existe ou não funcionalidade habitacional para as famílias que o ocupam. Para isso, normas técnicas sobre o uso de materiais para execução de estruturas de concreto 
armado foram consultadas, além da realização de uma extensa revisão bibliográfica sobre o surgimento e classificação dos tipos de manifestações patológicas, principalmente no que tange as estruturas antigas.

Foram realizadas inspeções visuais para investigar a ocorrência de fissuras, corrosão das armaduras e degradação do concreto; classificação da estrutura e das manifestações patológicas segundo normas técnicas brasileiras; experimentos de cunho pouco ou não destrutivos, como o de dureza superficial do concreto, profundidade de carbonatação e aspersão de nitrato de prata.

\section{História local: edifício bom pastor}

O prédio do Bom Pastor está localizado a margem da BR 424, que apresenta tráfego intenso de carros nas suas imediações, na cidade de Garanhuns. A edificação, que contempla uma capela adjacente a sua estrutura, possui cerca de cento e cinco anos (105) anos de construída e é composta por alvenaria estrutural com blocos maciços e elementos de concreto armado.

O prédio teve sua inauguração em 1911, com 76 hectares (760.000 metros quadrados) de terreno localizado no sítio Mulungú, e operava como o instituto profissional agrícola chamado Aprendizado Agrícola e Pastoril Samuel Hardman, proveniente de subsídios do sindicado, governo do estado e governo federal, segundo arquivo da Biblioteca Nacional Digital [4].

De acordo com o mesmo acervo [5], após 1923, o terreno foi divido e vendido para o abrigo de três famílias imigrantes. Como mencionado na mensagem apresentada ao congresso legislativo de 1930, o mesmo prédio foi então reformulado para funcionar como a Escola Correcional de Garanhuns, onde, após sua inauguração, em 18 de outubro de 1929, o governo federal passou a instalar jovens detentos a fim de educá-los [6].

O Instituto Profissional Bom Pastor, compreendia uma área de cerca de 20 hectares (200.000 metros quadrados). Foi fundado por freiras da Congregação de Nossa Senhora da Caridade do Bom Pastor, por volta de 1942, com o intuito de abrigar e alfabetizar mulheres desabrigadas e carentes, na antiga sede do Patronato Agrícola de Garanhuns. Possuía uma capela, um prédio principal, que servia de dormitórios, além de salas para socialização, cozinha, área de recreação e área para atividades agrícolas, assim descritas pela escritora e antiga residente do Instituto, Rosilda Cavalcante [7].

O instituto teve funcionamento até a década de 1980, quando suas estruturas já ofereciam riscos aos seus moradores devido às condições precárias e a falta de verbas da diocese e do governo. Segundo acervo da Polícia Militar de Pernambuco, nesta época o batalhão instalou-se no local. Em 1987 a estrutura já não atendia mais às necessidades para o desenvolvimento de suas atividades e a partir deste momento não teve mais uso registrado [8].

O terreno do Bom Pastor, que antes pertencia ao governo do Estado, foi doado inteiramente à Universidade Federal Rural de Pernambuco (UFRPE UAG). Segundo Airon Melo, diretor geral da UFRPEUAG, existiu um projeto em 2010 para a construção do Parque Tecnológico e Cultural da Bacia leiteira de Pernambuco, em que o edifício se tornaria o Museu de Queijo de Coalho do Agreste. Contudo, Melo relatou também que o projeto não recebeu subsídios suficientes para executá-lo por completo. Foi construído apenas o Centro Tecnológico Instituto de Laticínios do Agreste (CT Laticínios), enquanto a reforma do prédio do Bom Pastor nunca foi iniciada [9].

Atualmente o local encontra-se abandonado, sem manutenção das estruturas, como podem ser vistas na Figura 1. Segundo a pesquisa bibliográfica realizada, não foi possível encontrar os indícios iniciais para tal situação precária, tão pouco o período de tempo em que algumas de suas estruturas desabaram.

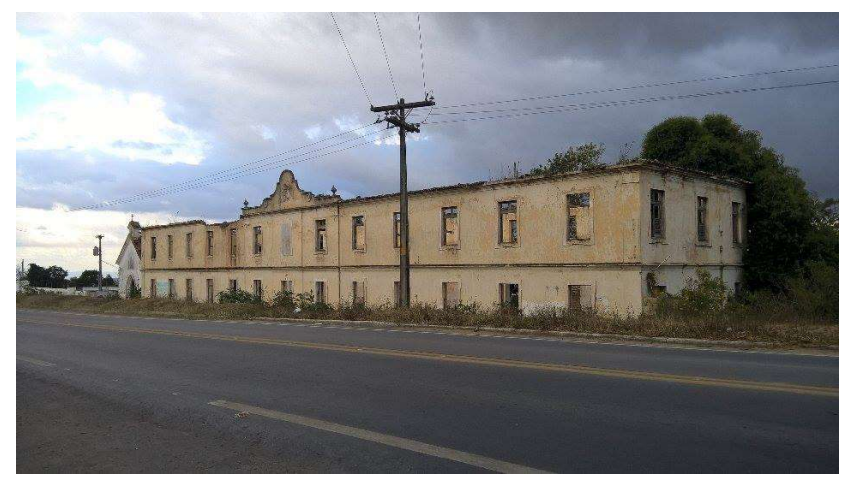

Figura 1: Edifício Bom Pastor.

Fonte: Autor, 2016

http: / /dx.doi.org/10.25286/repa.v2i3.691 


\section{Material e Métodos}

Como inspeção preliminar foi realizada uma análise visual, onde foram distinguidas as características das estruturas de concreto escolhidas, e as manifestações patológicas existentes em quatro peças de concreto armado: dois pilares (denominados P1 e P2), uma escada e uma marquise (avanço de laje).

Posteriormente, foram realizados ensaios de cunho pouco ou não destrutivos como o de avaliação de dureza superficial do concreto, profundidade de carbonatação e aspersão de solução de nitrato de prata para analisar os desgastes dos elementos do edifício em estudo. Uma inspeção preliminar também foi realizada, destacando assim, as variáveis para as causas das manifestações patológicas encontradas.

\section{Resultados e Discussão}

Decorrente da idade do edifício em estudo, não foram encontrados relatos sobre os projetos pertinentes e processos de execução, ou ainda, se houve uso de normativas técnicas. Então se supõe que foi construído de forma empírica, pois em 1911 ainda não haviam normas técnicas brasileiras.

Além disso, entende-se que as estruturas de concreto armado do Edifício Bom Pastor foram construídas em outro período diferente do de sua inauguração, decorrente de reformas no local.

Os Pilares P1 e P2, localizados no interior da edificação, ilustradas pela Figura 2 (A) e 2 (B), respectivamente, dão apoio a uma pequena laje do primeiro andar do prédio. Ambos pilares ficam expostos à chuvas e ventos devido a inexistência das estruturas das lajes vizinhas. Foi constatada a presença de fungos, como o bolor na superfície, devido associação entre a presença de microorganismos e a infiltração existente na estrutura.

O Pilar P2, também apresentou fissuras que se estendem de forma longitudinal à peça e de forma paralela à direção da armadura. Além de destacamento do concreto devido ao mecanismo da corrosão e expansão do aço.

Segundo Helene, os indícios de corrosão de armadura podem ser compreendidos como fissuras, destacamento do cobrimento, pontos com armadura exposta e perda de seção da bitola do aço [10].

A escada (Figura 3) foi a estrutura onde houve maior surgimento de manifestações patológicas. Está localizada na entrada do prédio, também a céu aberto, onde os usuários ainda transitam sobre ela. O nível de deterioração do revestimento se encontra bastante elevado apresentando todos os indícios de corrosão de armadura, definidos pelo mesmo autor [10].

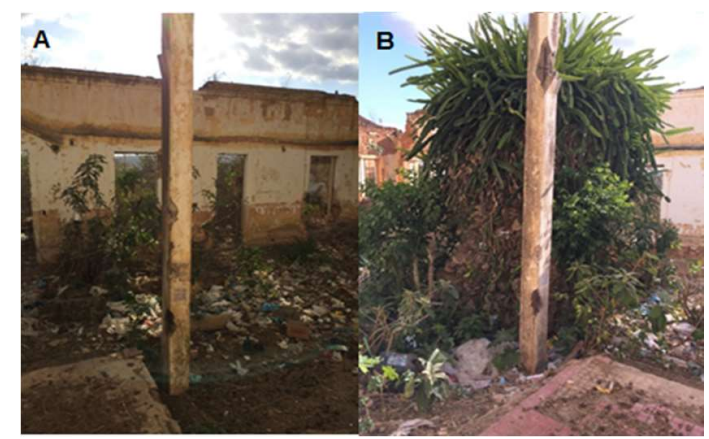

Figura 2: Pilares $P 1(A)$ e $P 2(B)$.

Fonte: Autor, 2016.

Além do cobrimento ineficiente, foi observado o aparecimento de eflorescência, causadas pela lixiviação do concreto. A Eflorescência é um mecanismo de degradação e envelhecimento do concreto, resultante de infiltrações e intempéries, que provoca a formação de depósitos salinos em sua superfície e a modificação da cor do substrato para um aspecto esbranquiçado, como descreveu Gonçalves [11].

A lixiviação provoca diminuição do $\mathrm{pH}$ da massa de cimento e aumento da sua porosidade, como consequência facilita a entrada de agentes agressores e o contato com a armadura, que, segundo Mizumoto, possibilita o processo de despassivação e corrosão da armadura [12].

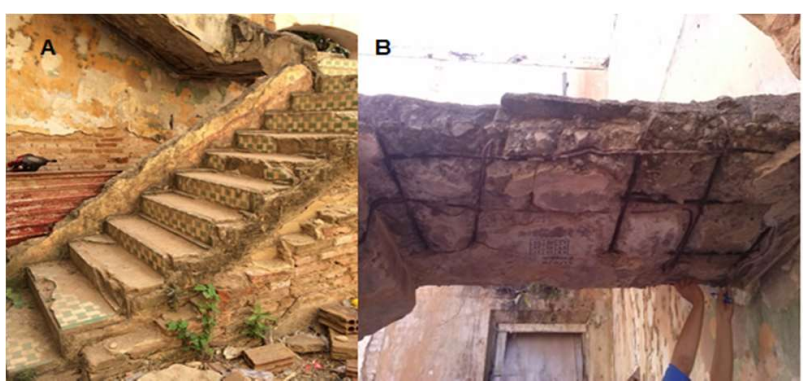

Figura 3: Revestimento danificado nos patamares da escada (A); Fundo da escada com falta de cobrimento e exposição da armadura (B).

Fonte: Autor, 2016.

A marquise (Figura 4), se situa na parte oeste do prédio, onde existem muitas plantas daninhas. Devido ao contexto na qual está inserida, com forte influência 
de chuvas, ventos e detritos de animais, possui a maior predisposição a apresentar infiltrações. Foram visualizadas manifestações de forma intensa como bolor de forma, manchas esbranquiçadas devido a eflorescência, destacamento do concreto, além de armaduras expostas e corroídas.

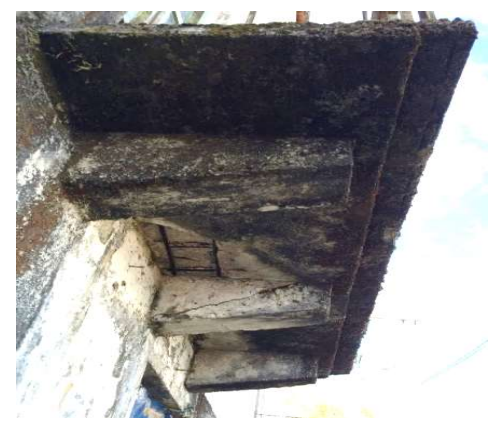

Figura 4: Marquise.

Fonte: Autor, 2016.

Foi verificado o cobrimento real com concreto das armaduras, das estruturas dos pilares, escada e marquise e então relacionadas ao cobrimento estimado segundo as normas técnicas atuais, NBR 6118/2014, devido à interação com o nível de agressividade do ambiente a qual a estrutura está inserida [13], os resultados dessa análise comparativa podem ser verificados na Figura 5.

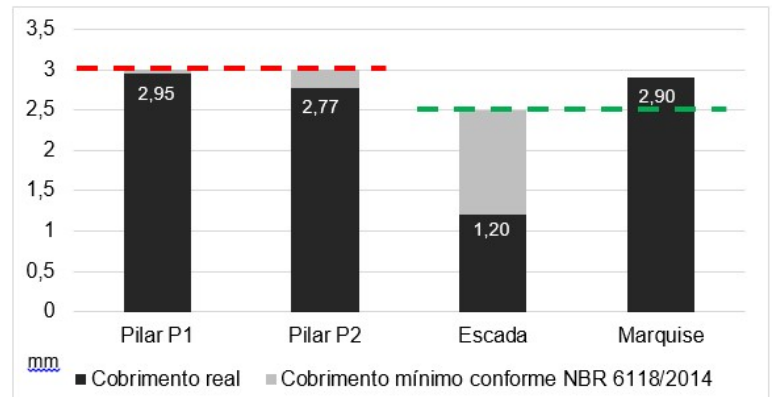

Figura 5: Relação entre cobrimentos reais e cobrimentos mínimo à luz da norma NBR 6118/2014

Fonte: Autor, 2016.

A linha tracejada vermelha indica o cobrimento mínimo em relação à norma para os pilares, enquanto a linha verde tracejada indica o cobrimento mínimo em relação às lajes. Foi observado que todas as estruturas, com exceção da marquise, não atenderam à normativa da NBR 6118/2014 uma vez que o cobrimento mínimo necessário se encontra abaixo do estipulado pela norma.
No caso da marquise, cujo valor do cobrimento real ultrapassou o requerido em norma, a sua espessura não foi o motivo primordial para as manifestações patológicas apresentadas, mas sim o material que foi utilizado para fabricação do concreto bem como sua alta porosidade que propicia a entrada de agentes agressivos do meio.

\subsection{Fissuras}

A estrutura se encontra em uma classe de agressividade ambiental moderada, por estar em um meio urbano, portanto, segundo a NBR 6118, a espessura máxima para uma fissura não ser considerada agressiva é inferior a 0,3mm [13]. Sua nomenclatura é definida segundo NBR 9575 (ABNT, 2010), como: fissuras (inferior ou igual a 0,5 mm), e tricas (superior a 0,5 mm e inferior a $1 \mathrm{~mm}$ ) [14].

As espessuras das fissuras do Pilar P2 e Escada foram medidas por um comparador de fissuras (fissurômetro) e classificadas como agressivas e trincas como demostra a Tabela 1.

Tabela 1: Classificação das fissuras segundo o comparador de fissuras

\begin{tabular}{l|l|l|l}
\hline Estrutura & $\begin{array}{l}\text { Comparador } \\
\text { de fissuras }\end{array}$ & $\begin{array}{l}\text { Classificação } \\
\text { segundo NBR } \\
\mathbf{6 1 1 8 / 2 0 1 4}\end{array}$ & $\begin{array}{l}\text { Classificação } \\
\text { segundo NBR } \\
\mathbf{9 5 7 5 / 2 0 1 0}\end{array}$ \\
\hline Pilar P2 & $1,4 \mathrm{~mm}$ & Agressiva & Trinca \\
\hline Escada & $0,8 \mathrm{~mm}$ & Agressiva & Trinca \\
Fonte: Autor, 2016. &
\end{tabular}

Acrescentando a estas classificações, Dalmolin, notou em suas pesquisas, que a quantidade de fissuras não deve ser levada em conta, mas sim o aspecto qualitativo [15]. Dependendo dos respectivos potenciais destrutivos, as fissuras podem ser extremamente graves e comprometer a integridade da construção. Além disso, podem servir de caminho para entrada de agentes agressivos e de umidade, causando outros tipos de manifestações patológicas.

\subsection{Avaliação de dureza superficial do concreto}

Como cita a NBR 7584, no ensaio de esclerômetro, é medida a dureza superficial do concreto e estimada a resistência à compressão superficial do mesmo por meio do princípio do ricochete [16].

http: / / dx.doi.org/10.25286/repa.v2i3.691 
Foi utilizado o esclerômetro do tipo Schmidt e realizada preparação da superfície, utilizando disco de carborundum, para lixar e posteriormente limpar de modo que não permanecesse nenhuma irregularidade. Realizaram-se dezesseis impactos sobre cada estrutura e então calculados seus Índices Esclerométricos relacionados ao valor de coeficiente de correção para estimar a resistência de compressão superficial do concreto.

Ao retirar o revestimento das peças dos Pilares $\mathrm{P} 1$ e P2, o concreto aparentou ter maior quantidade de britas e pouca pasta de cimento, além da alta porosidade aparente. Teve como resultado índices esclerométricos diferentes ao longo da seção, e por isso não foi possível obter os resultados das resistências destas peças. Pois de acordo com a norma NBR 7584, se faz necessário ter no mínimo cinco valores dentro da média real [16].

Os resultados do ensaio para a Escada também não puderam ser considerados válidos, já que pela mesma norma, a média mínima aceitável para realização do ensaio de esclerômetro é 20 e o valor médio dos índices esclerométricos para esse elemento construtivo foi de 16,83 .

Para determinação da resistência superficial da Marquise, foi calculado o valor de 24,03 Mpa. Apesar da estrutura ter sido realizada segundo normas da época que foi construída, com relação a referência para valor mínimo da resistência, que provavelmente não mencionavam requisitos de durabilidade, se comparada a norma brasileira atual NBR 6118, seu concreto deveria ter resistência mínima de $25 \mathrm{Mpa}$.

Portanto, segundo requisitos atuais, o concreto da marquise está propenso à fissuração e possivelmente colapso da estrutura, pois não atende aos requisitos de durabilidade para o tipo de agressão a qual a estrutura está inserida.

Ainda de acordo com a norma NBR 7584, os aspectos que influenciam o teste de esclerômetro estão relacionados aos materiais constituintes do concreto, como agregados, cimento, água, armadura e aditivos, como também a idade da estrutura, umidade, temperatura, tensões, a forma do uso do aparelho, cura do concreto e presença de carbonatação [16].

\subsection{Corrosão das armaduras}

Gentil, define "corrosão como a deterioração de um material, geralmente metálico, por ação química ou eletroquímica do meio ambiente aliada ou não a esforços mecânicos" [17].

Fusco, acrescenta que o aço possui uma película passivadora capaz de proteger sua integridade por meio do controle do $\mathrm{PH}$ e o aço só poderá sofrer corrosão se:

- Houver redução do $\mathrm{pH}$, abaixo de 9, por efeito da carbonatação da camada de cobrimento da armadura;

- $\quad$ Presença de íons cloreto $(\mathrm{Cl})$ ou de poluição atmosférica acima de um valor crítico;

- Lixiviação do concreto na presença de fluxos de água que percolem através de sua massa [18].

O processo de carbonatação no concreto surge pela infiltração de dióxido de carbono (CO2) por seus poros, diminuindo o seu $\mathrm{pH}$, que usualmente apresenta-se acima de 12,5 e reduz para valores abaixo de 9. Desta forma, transforma-o em alcalino, que reage na presença de potássio $(\mathrm{KOH})$, hidróxido de cálcio $(\mathrm{Ca}(\mathrm{OH}) 2)$ e de sódio $(\mathrm{NaOH})$, a níveis que atingindo a armadura pode desenvolver corrosão do aço, como explica o pesquisador Possan [19].

Para o ensaio de carbonatação nas estruturas de concreto armado encontradas no edifício em estudo, foram realizadas aberturas de modo que a armadura ficou exposta e pode ser observado o seu cobrimento.

Segundo Silva, A solução alcoólica de fenolftaleína quando borrifada sobre estruturas de concreto servem como indicador ácido-básico, por meio de mudança de cor, que dependendo do $\mathrm{pH}$ da estrutura pode se apresentar incolor quando ácido (apresentar indícios de carbonatação) e com coloração rosa quando básico (concreto não afetado pelo CO2) [20]. Foram executados ensaios de profundidade de carbonatação por meio de aspersão de fenoftaleína.

Nos Pilares P1 e P2, o ensaio resultou na coloração rosa apenas na parte superficial da peça, mostrando que está presente apenas no revestimento dos pilares, enquanto o concreto em si apresenta-se incolor até a armadura comprovando que houve despassivação do aço devido a agressão do CO2, como pode ser notado na Figura 6. 


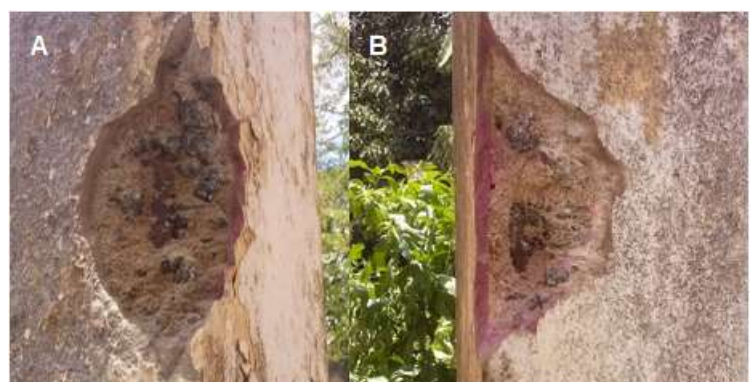

Figura 6: Ensaio de profundidade de carbonatação nos pilares P1 (A) e P2 (B)

Fonte: Autor, 2016.

Com isso, pode-se dizer que esse revestimento é mais recente do que o concreto, de forma atípica, supondo que estes pilares já passaram por alguma recuperação dos revestimentos e por isso ainda não apresentaram carbonatação.

As aberturas realizadas na escada e marquise, Figura 7, apresentaram carbonatação em sua totalidade, devido a cor incolor ser a única visualizada.

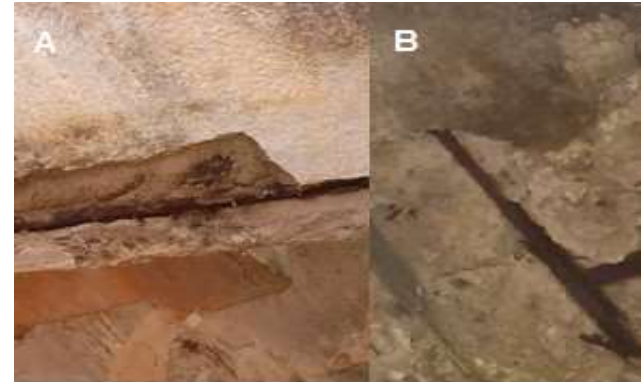

Figura 7: Ensaio de profundidade de carbonatação na escada (A) e marquise (B).

Fonte: Autor, 2016.

Tais resultados são observados devido à aspectos relacionados com a idade da estrutura, pois quanto mais tempo o concreto encontra-se exposto, mais propenso ele estará a receber dióxido de carbono.

Foi observado também que a cidade de Garanhuns possui umidade relativa do ar elevada, o que intensifica a probabilidade de agentes agressivos presentes no meio de se transportem pelos poros das estruturas de concreto. Outra característica devido à sua localização é a presença de dióxido de carbono no ar, através de poluição e trânsito de veículos pela BR 424, situada nas adjacências do terreno, comprovado pelo ensaio com solução de fenolftaleína.

O aparecimento de eflorescência devido a lixiviação nas estruturas da escada e marquise, resultaram em perda de resistência e maior 90 porosidade das mesmas, facilitando a carbonatação do concreto e corrosão das armaduras.

Assim como a carbonatação, os íons de cloretos também podem penetrar na massa do concreto, pelos poros, podendo eles estarem saturados ou parcialmente saturados.

São originários da água do mar ou de poluentes ambientais e podem chegar a corroer as armaduras presentes na estrutura, porém de forma mais agressiva, pois suas partículas de cloretos não são consumidas pela reação e agem como catalizadores para a corrosão, conclui Fusco [18].

França complementa que o método de Aspersão de Solução de Nitrato de Prata (AgNO3), consiste em determinar a presença de cloretos livres, podendo ser realizada "in loco" sendo menos dispendiosa do que em relação aos ensaios em laboratório. Porém, não detecta a sua quantidade, apenas a existência de sua presença [21].

Foi realizado o ensaio com solução de nitrato de prata, com concentração de 0,1 mol/l, equivalente a $17 \mathrm{~g}$ de $\mathrm{AgNO} 3$ para 1 litro de água destilada. Foram realizadas aberturas nas estruturas e então aspergida a substância. O parâmetro adotado foi a cor esbranquiçada do nitrato de prata para indicar presença de cloretos livres no concreto e a coloração marrom escura para indicar o local onde a estrutura não estava afetada.

Nenhuma das estruturas analisadas apresentou incidência de cloretos após a realização do ensaio. A coloração visualizada foi apenas a marrom e a coloração dos agregados graúdos da massa de concreto, como pode ser notado na Figura 8.

A não influência da ação de cloretos na estrutura se verifica devido ao fato da cidade de Garanhuns se encontrar no interior de Pernambuco e, portanto, distante do mar, principal agente concentrador de cloretos. As estruturas do Bom Pastor sofrem influência em relação ao ciclo de molhagens e secagens, assim como o de chuvas, no entanto, por não apresentar precipitações de cloretos, admite-se que os ventos e chuvas locais não possuem cloretos, garantindo que o aço nesta região não sofra corrosão de forma mais agressiva.

http: / /dx.doi.org/10.25286/repa.v2i3.691 


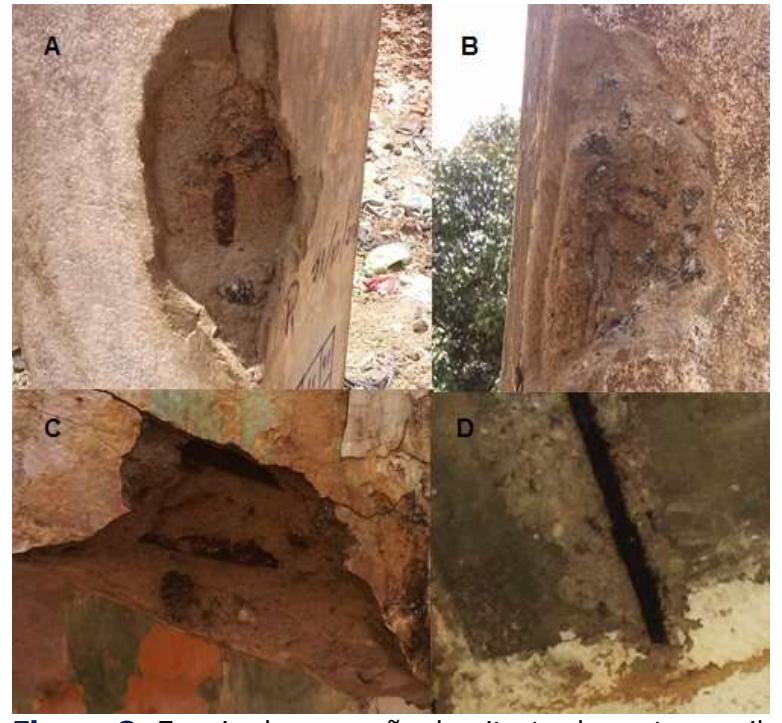

Figura 8: Ensaio de aspersão de nitrato de prata no pilar P1 (A), pilar P2 (B), escada (C) e marquise (D)

Fonte: Autor, 2016.

Todavia, este ensaio não obtém resultados muito precisos devido à falta de retirada de testemunhos e verificação detalha em laboratório, como nos ensaios de penetração de cloretos, que segundo a norma americana ASTM C 1152, consiste no estudo de camadas de testemunhos retirados do concreto $\mathrm{e}$ coleta do material da face que esteve em contato com a solução de cloreto de sódio para poder determinar o teor de cloretos totais retidos [22].

\section{Conclusões}

Por ser uma estrutura antiga, com mais de cem anos de construída, a vida útil da estrutura do Bom Pastor já não atende mais aos padrões convencionais de durabilidade. A qualidade do concreto influi para o aparecimento de manifestações patológicas, desde a forma de planejamento e execução até a sua manutenção. Foi percebido que ao longo do tempo houveram reformas, porém não houveram investimentos posteriores para o contínuo uso desta estrutura.

As estruturas analisadas no edifício Bom Pastor (dois pilares, uma escada e uma marquise) apresentaram diversas manifestações patológicas, incluindo trincas, surgimento de bolor e eflorescência, baixa resistência superficial e corrosão das armaduras.

Além das manifestações leva-se em conta a precariedade do local, onde são encontrados lixos, fossas artesanais e detritos de animais, por este motivo é considerada inapta para habitação.

Devido aos resultados obtidos, a estrutura é considerada imprópria ao uso e os elementos analisados já não atendem a sua funcionalidade. O edifício não teve a manutenção necessária e estabilidade para ser considerada habitacional, com isto, as pessoas que moram nesta área correm riscos tanto de segurança quanto riscos à saúde.

Pelo exíguo tempo de elaboração desta pesquisa, com aproximadamente três meses para planejamento, coleta de dados, visitas in loco e conclusão, foi escolhido não proceder os ensaios de análise na capela e nos ambientes ocupados pelas famílias que habitam no local para não causar maior degradação nas estruturas.

Algumas perspectivas para pesquisas futuras seriam continuar os estudos sobre as manifestações patológicas no edifício, nos ambientes onde estão ocupadas pelas famílias e na capela que fica anexada ao prédio Bom Pastor, assim como pesquisar de forma mais aprofundada sobre a vida útil do local. Também analisar a viabilidade econômica e maneiras de restauração do edifício e investigar meios de alocação das pessoas para locais dignos e seguros.

\section{Referências}

[1] LIMA, S.; SIQUEIRA, W. Manifestações Patológicas em laje de cobertura: estudo de caso. In: CONGRESSO INTERNACIONAL SOBRE PATOLOGIAS E REABILITAÇÃO EM ESTRUTURAS, 2010, Córdoba, Argentina. Cuiabá, Mato Grosso, 2010.

[2] MOREIRA, K. A. W. Estudo das Manifestações Patológicas na Produção de Pré-Fabricados de Concreto. 2009. Dissertação (Mestrado em Engenharia de Materiais) - Programa de Pósgraduação em Engenharia Mecânica e de Materiais, Universidade Tecnológica Federal do Paraná Campus de Curitiba. Curitiba, 2009. 
[3] SOUZA, V.; RIPPER, T. Patologia, Recuperação e Reforço de Estruturas de Concreto. São Paulo: PINI, 1998.

[4] BIBLIOTECA NACIONAL DIGITAL (Brasil). Mensagem de Manoel Antônio Pereira Borba, apresentada ao congresso legislativo em 06 de março de 1919. Relatório dos Presidentes dos Estados Brasileiros - 1890 a 1930. Disponível em: $<$

http://memoria.bn.br/DocReader/DocReader.asp $x$ ?bib $=720461>$ Acesso em: 24 de outubro de 2016.

[5] . Mensagem de Sérgio Lins Loreto, apresentada ao congresso legislativo em 06 de março de 1925. Relatório dos Presidentes dos Estados Brasileiros - 1890 a 1930. Disponível em: <http://memoria.bn.br/DocReader/DocReader.as px?bib $=720461>$ Acesso em: 24 de outubro de 2016.

[6] Mensagem de Estácio de Albuquerque Coimbra, apresentada ao congresso legislativo em 03 de abril de 1930. Relatório dos Presidentes dos Estados Brasileiros - 1890 a 1930. Disponível em: < http://memoria.bn.br/DocReader/DocReader.asp $x$ ?bib $=720461>$ Acesso em: 24 de outubro de 2016.

[7] CAVALCANTI, R. Instituto Profissional Bom Pastor: Um aspecto da educação feminina católica em Garanhuns. Blog Garanhuns, 2010. Disponível em:

https://terradomagano.blogspot.com.br/2010/09 /convento-do-bom-pastor-

educacao. html?showComment $=1462888025506$

$>$. Acesso em: 14 de outubro de 2016 .

[8] POLÍCIA MILITAR DE PERNAMBUCO. Acervo referente ao período de 21 de janeiro de 1980 a 01 de setembro de 1982 da antiga $4^{a} \mathrm{CIA} / 3^{\circ} \mathrm{BPM}$, 1980.

[9] MELO, A. A. Projeto Tecnológico e Cultural da Bacia Leiteira de Pernambuco. Garanhuns: Universidade Federal Rural de Pernambuco -
Unidade Acadêmica de Garanhuns, 2016. (Comunicação verbal).

[10] HELENE, P. R. L. Corrosão em armaduras para concreto armado. São Paulo: Pini, 1999.

[11] GONÇALVES, E. A. B. Estudo de patologias e suas causas nas estruturas de concreto armado de obras de edificações. 2015. Dissertação (Graduação apresentado ao Curso de Engenharia Civil) - Escola Politécnica, Universidade Federal do Rio de Janeiro. Rio de Janeiro, 2015.

[12] MIZUMOTO, C. Investigação da Reação Álcali-Agregado (RAA) em Testemunhos de Concreto e Agregados Constituintes, 2009. Dissertação (Mestrado em Engenharia Civil, Curso de Pós-Graduação) - Universidade Estadual Paulista, Ilha Solteira, 2009.

[13] ASSOCIAÇÃO BRASILEIRA DE NORMAS TÉCNICAS. NRB 6118 - Projeto de estruturas de concreto - Procedimento, Rio de Janeiro, 2014. Disponível em: <http://www.abnt.br>. Acesso em: 18 de agosto de 2016.

[14] NBR 9575 - Impermeabilização Seleção e projeto, Rio de Janeiro, 2010. Disponível em: <http://www.abnt.br>. Acesso em: 28 de setembro de 2016.

[15] DALMOLIN, D. Fissuras em estruturas de concreto armado: análise das manifestações típicas e levantamento de casos ocorridos no estado do Rio Grande do sul. 1998. Dissertação (Mestrado em Engenharia, Pós-graduação em engenharia civil) - Escola de Engenharia, Universidade Federal do Rio Grande do Sul, Porto Alegre, 1988.

[16] ASSOCIAÇÃO BRASILEIRA DE NORMAS TÉCNICAS. NBR 7584 - Concreto endurecido Avaliação da dureza superficial pelo esclerômetro de reflexão - Método de ensaio, Rio de Janeiro, 2012. Disponível em: <http://www.abnt.br> Acesso em: 27 de outubro de 2016.

[17] GENTIL; V. Corrosão. 4. ed. Rio de Janeiro: LTC Editora, 2003.

http://dx.doi.org/10.25286/repa.v2i3.691 
[18] FUSCO, P. B. Tecnologia do Concreto Estrutural. 2 ed. São Paulo: PINI, 2012.

[19] POSSAN, E. Contribuição ao Estudo da Carbonatação do Concreto com Adição de Sílica Ativa em Ambiente Natural e Acelerado. 2004. Dissertação (Mestrado em Engenharia Civil) Universidade Federal do Rio Grande do Sul, Porto Alegre, 2004.

[20] SILVA, C. A. Comportamento dos Perfis de Cloreto em Tetrápodes localizados nos Molhes da Barra. 2010. Dissertação (Mestrado em Engenharia Oceânica) - Programa de Pósgraduação em Engenharia Oceânica, Universidade Federal do Rio Grande, Rio Grande, 2010.

[21] FRANÇA, C. B. Avaliação de Cloretos Livres em Concretos pelo Método de Aspersão de Solução de Nitrato de Prata. 2011. Dissertação (Mestrado em Engenharia Civil) - Programa de Pós-graduação em Engenharia Civil - Universidade Católica de Pernambuco, Recife, 2011.

[22] AMERICAN SOCIETY FOR TESTING OF MATERIALS. Standard test method for acidsoluble chloride in mortar and concrete - ASTM C1152-90. 